\title{
DIFUSÃO DE MATERIAL INFORMATIVO SOBRE O DESCARTE DE RESÍDUOS RADIOLÓGICOS ENTRE ACADÊMICOS DE ODONTOLOGIA E CIRURGIÕES-DENTISTAS DA REGIÃO SUL DO BRASIL
}

\author{
BOHNER, L.O.L' ${ }^{1}$; BOHNER, T.O.L. ${ }^{2}$; PERES, P. ${ }^{3}$ \\ ${ }^{1}$ Estudante de Graduação em Odontologia (UFSC). \\ ${ }^{2}$ Estudante de Pós- Graduação em Educação Ambiental (UFSM). \\ ${ }^{3}$ Professor de Pós - Graduação em Educação Ambiental (UFSM) - Universidade Federal de Santa Maria
}

\section{RESUMO}

O material de radiologia utilizado em consultórios odontológicos produz risco ambiental quando não descartado de forma correta, pois a prata, presente em soluções químicas utilizadas durante o processo de revelação, é considerado tóxico para o ser humano. O gerenciamento dos Serviços de Saúde é o processo utilizado para minimizar os efeitos adversos causados pelos resíduos tóxicos, diminuindo o impacto ambiental. É importante que os profissionais da saúde conheçam o processo de descarte, de forma que essa conscientização deve ocorrer ainda no meio acadêmico. O presente estudo tem como objetivo difundir informações sobre o Gerenciamento de Resíduos de Serviços de Saúde entre os acadêmicos de Odontologia e cirurgiões-dentistas. Foram confeccionados cartazes e panfletos sobre o impacto ambiental causado pelo descarte incorreto dos resíduos radiológicos e o gerenciamento dos Resíduos de Serviços de Saúde, e distribuídos nas Faculdades de Odontologia da Universidade Federal de Santa Catarina (UFSC), Universidade Federal de Santa Maria (UFSM), e nos Consultórios Odontológicos das cidades de Florianópolis, SC, e Santa Maria, RS. Os panfletos foram distribuídos em cem consultórios, e seis cartazes foram distribuídos nos Institutos de Ensino Superior. Programas de orientação são necessários para conscientizar os profissionais sobre a conduta adequada para o descarte de resíduos, assim como o impacto ambiental causado pelo não cumprimento da mesma.

Palavras - chave: resíduos odontológicos, impacto ambiental 


\section{REGETUFSM}

Rev. Elet. em Gestão, Educação e Tecnologia Ambiental

(e-ISSN: 2236-1170)

\section{INTRODUÇÃO}

O uso de filmes radiográficos na Odontologia é muito benéfico, por auxiliar na obtenção do diagnóstico e na realização de diversos tratamentos (FERNANDES, 2009). Entretanto, os efluentes líquidos utilizados no processo de revelação radiográfica contém metais pesados acima do permitido para o descarte (OLIVEIRA, 2006), podendo representar um fator de risco para a saúde de organismos aquáticos e terrestres (MACIEL, 2004), através da contaminação do solo e águas superficiais e subterrâneas (Gerenciamento dos resíduos de serviços de saúde, 2006). A água utilizada no processo de lavagem também contém resquícios das soluções, o que a torna carente de tratamento antes de ser lançada na rede de esgoto (OLIVEIRA, 2006; FERNANDES, 2009). Assim, estes efluentes são considerados prejudiciais ao meio ambiente quando não descartados corretamente (OLIVEIRA, 2006; RAMALHO, 2010; FERNANDES, 2009).

O gerenciamento é o processo que visa minimizar ou impedir os efeitos dos Resíduos de Serviços de Saúde no meio ambiente (OLIVEIRA, 2006). A resolução RDC ANVISA n 306 dispõe sobre o gerenciamento interno e externo dos Resíduos de Serviços de Saúde, incluindo os efluentes utilizados para o processamento de radiografias (Gerenciamento dos resíduos de serviços da saúde, 2006). Geradores deste tipo de resíduos devem atender à resolução, minimizando, assim, o impacto ambiental provocado pelos mesmos (OLIVEIRA, 2006).

Estudos realizados por MAMELUQUE (2007) em Montes Claros, MG, verificou que a maioria dos profissionais descarta resíduos químicos na rede de esgoto, sem tratamento anterior. O não cumprimento da resolução da ANVISA ocorre pela falta de conhecimento sobre o assunto (PIRES et al., 2010), além da falta de infra-estrutura para realizar adequadamente o gerenciamento dos resíduos de serviços de saúde (GARCIA et al., 2004).

Tendo em vista o impacto ambiental causado pelas soluções químicas utilizadas no serviço radiológico, assim como suas consequências na saúde da população, o objetivo do presente estudo é orientar profissionais e acadêmicos da área odontológica sobre o descarte adequado dos resíduos radiológicos, através da difusão de materiais informativos distribuídos nas cidades de Florianópolis, SC, e Santa Maria, RS. 


\section{REGETUFSM}

Rev. Elet. em Gestão, Educação e Tecnologia Ambiental

(e-ISSN: 2236-1170)

\section{METODOLOGIA}

O programa de orientação sobre o descarte de resíduos radiológicos ocorreu nas cidades de Florianópolis, Santa Catarina, e Santa Maria, Rio Grande do Sul. A população-alvo consistiu de acadêmicos de Odontologia da Universidade Federal de Santa Catarina (UFSC), acadêmicos de Odontologia da Universidade Federal de Santa Maria (UFSM), e profissionais da área odontológica. Foram confeccionados e distribuídos cartazes e panfletos, informando sobre o impacto ambiental causado por resíduos radiológicos, e a importância do correto descarte dos mesmos. Além disso, foi desenvolvido um protocolo sobre os passo a passo que deve ser seguido pelos profissionais da saúde.

\section{RESULTADOS E DISCUSSÃO}

Cem panfletos foram confeccionados, e distribuídos nos Consultórios Odontológicos das cidades de Florianópolis, SC, e Santa Maria, RS. Com isso, espera-se ter atingido aproximadamente 200 cirurgiões- dentistas. Segundo Mameluque (2007), há necessidade de implementar programas de orientação sobre o descarte de resíduos radiológicos.

Visto que a orientação deve ocorrer ainda no meio acadêmico, seis cartazes foram distribuídos nas Faculdades de Odontologia da Universidade Federal de Santa Catarina e Universidade Federal de Santa Maria. As clínicas odontológicas são locais onde passam, diariamente, uma grande quantidade de estudantes, sendo, por isso, o local de escolha para a colocação dos cartazes.

Segundo Fernandes (2009), os cirurgiões-dentistas não cumprem seu papel no gerenciamento de produtos radiológicos, e o desconhecimento sobre o descarte adequado é quase completo. Assim, espera-se, com a divulgação, conscientizar profissionais da saúde e acadêmicos sobre o impacto ambiental decorrente do descarte inadequado de resíduos odontológicos.

\section{CONCLUSÃO}

O não cumprimento da resolução da ANVISA ocorre pela falta de conhecimento sobre o gerenciamento dos resíduos de serviços de saúde. Programas de orientação são necessários para 
conscientizar acadêmicos de Odontologia e cirurgiões-dentistas sobre o descarte adequado de resíduos radiológicos, assim como o impacto ambiental causado pelo não cumprimento do mesmo.

\section{REFERÊNCIAS}

1. BORTOLETTO, E.C.; TAVARES, C.R.G.; BARROS, M.A.S.D.; CARLI, C.M. “Caracterização da geração e da qualidade do efluente líquido gerado no laboratório de raio-x da clínica odontológica do Hospital Universitário de Maringá". In: VI CONGRESSO BRASILEIRO DE ENGENHARIA QUÍMICA EM INICIAÇÃO CIENTÍFICA. Anais, 2005.

2. BRASIL, Agência Nacional de Vigilância Sanitária. Resolução - ANVISA. RDC no 306, de 07 de dezembro de 2004.

3. FERNANDES, M.F. "Conhecimento dos formandos em odontologia sobre o gerenciamento de resíduos de serviços de saúde- aspectos éticos e legais". Monografia apresentada para obtenção do Título de Especialista em Odontologia Legal, Unicamp, 2009.

4. FERNANDES, G.S.; AZEVEDO, A.C.P.; CARVALHO, A.C.P.; PINTO, M.L.C. "Análise e gerenciamento de efluentes de serviços de radiologia". Radiol Bras. v.38, n.5, p. 355-358, 2005.

5. GARCIA, L.P.; ZANETTI-RAMOS, B.G. “ Gerenciamento dos resíduos de serviços de saúde: uma questão de biossegurança". Cad. Saúde Pública, Rio de Janeiro, 20(3):744-752, 2004.

6. "Gerenciamento dos resíduos de serviços de saúde". 2006. Disponível em www.anvisa.gov.br, acesso em 01/06/2011, às 19:00.

7. HOCEVAR, C.M.; RODRIGUEZ, M.T.R. “Avaliação do impacto ambiental gerado por efluentes fotográficos, gráficos e radiológicos em Porto Alegre, RS, Brasil”. Eng Sanit Amb. v . 7, n. 3 e 4, p.139-143, 2002.

8. LIPPEL, M.; BAASCH, S. “Modelo de gerenciamento de resíduos sólidos de saúde para pequenos geradores: $\mathbf{O}$ caso de Blumenau/ SC". Dissertação apresentada ao programa de Pós-graduação em Ciência e Engenharia de Produção,UFSC; 2003. 
9. MACIEL, V.C.; LIU A.S.; CARDOSO P.G. "Tratamento do resíduo de prata de fixador radiográfico dental”. In: IX Encontro Latino Americano de Iniciação Científica e V Encontro Latino Americano de Pós- Graduação, 2004.

10. MAMEluQUe, S.; PORDEUS, I.A.; NOGUeIRA-MOReIRA, A.; MAGALHÃES, C.S. “Gerenciamento dos resíduos gerados nos consultórios odontológicos na cidade de Montes Claros". ABO Nac; 15(4), 2007.

11. OLIVEIRA P.C. “ Avaliação dos níveis de poluição ambiental dos serviços com radiologia odontológica na cidade de Itabuna - Bahia". Dissertação apresentada ao Programa de Pós- graduação em Desenvolvimento Regional e Meio Ambiente, Universidade Estadual de Santa Cruz; 2006.

12. PIRES, T.S.L.; GOULART, F.; LESSEI, J.; FELISBINO, J.; SOLONYNSKA, M. “A gestão dos resíduos de serviços de saúde como compromisso ambiental no curso superior de tecnologia em Radiologia". 2010. Disponível em www.sbpcnet.org.br, acesso dia 10/06/11, às 10:00.

13. Portal da saúde. Disponível em www.portal.saude.gov.br, acesso em 10/06/11, às 15:00.

14. RAMALHO, L.; UHLMANN, V.O.; PFITSCHER, E.D.; RABELO, E.C. “Avaliação da sustentabilidade dos aspectos e impactos ambientais de seriços odontológicos: Um estudo de caso". Reflexão Contábil, Vol. 29(1) , 2010.

15. SANTOS PEREIRA, N.R. "Levantamento das condições de biossegurança em radioproteção nos consultórios odontológicos de Campo Grande/MS". Dissertação apresentada ao Programa de Pós - graduação em Ciências da Saúde, Convênio Rede CentroOeste; 2008. 